\title{
Simple preparation of new piperidine derivatives as AChE inhibitors for pest control
}

\author{
Leonor Yamile Vargas Méndez ${ }^{\mathrm{a} *}$, Vladimir V. Kouznetsov \\ ${ }^{a}$ Grupo de Investigaciones Ambientales, Universidad Santo Tomas, A.A. 1076, Bucaramanga, Colombia. \\ ${ }^{b}$ Laboratorio de Química Orgánica y Biomolecular, Universidad Industrial de Santander, Cra 27 Calle 9, A.A. \\ 687, Bucaramanga, Colombia. \\ =leyavar@gmail.com
}

Keywords: piperidine derivatives, AChE inhibitors, insecticidal activity

\section{INTRODUCTION}

The use of synthetic insecticides in agriculture over the years has resulted in the development of resistance in insect pest populations and environmental problems. Therefore, it is highly desirable to develop new selective insecticidal agents based on natural products. Piperidine alkaloids occur widely in plants as well as in the animal kingdom. Due to their great diversity in biological and pharmacological activities, piperidine alkaloids and synthetic piperidines containing various substitution patterns are considered interesting target structures for pesticides development. A major use of AChE inhibitors takes place in agriculture where they are used for the control of insects and some other arthropod pests. Insecticidal activity is based on the overstimulation of the cholinergic system in the insect. ${ }^{1}$ Based on these facts and the previous results obtained by our group, ${ }^{2}$ we decided to address the design and synthesis of new piperidine molecules series as possible AChEls.

\section{RESULTS AND DISCUSSION}

Final piperidine compounds 5-8 were prepared starting from piperidine molecules such as simple piperidine 1, N-Bn-4-PhNHpiperidine 2 and N-Bnspiropiperidine $3^{2}$ and benzaldehydes 4 using onepot Strecker reaction catalyzed by $5 \% \mathrm{~mol} \mathrm{InCl}_{3}$ in $\mathrm{MeCN}$ as a key step after benzylation reaction of comp. 2,3 under mild conditions $\left(\mathrm{HCOONH}_{4} / \mathrm{Pd} / \mathrm{C}\right.$, $\mathrm{MeOH})$ (Scheme 1).

Scheme 1. Synthesis of new piperidine molecules series.

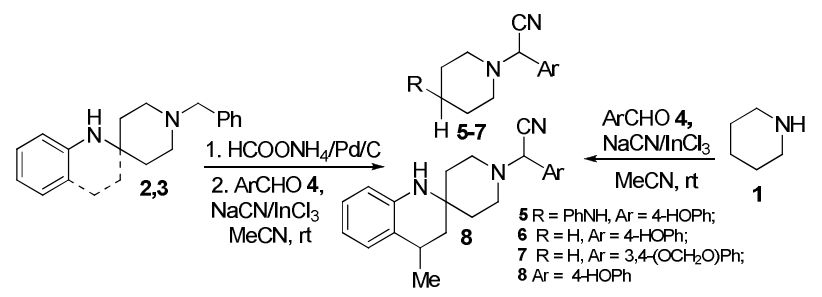

Target piperidine compounds synthesized were tested for inhibition of AChE activity level using the Ellman assay. ${ }^{3}$ This colorimetric assay is based on chromophores generated in situ after enzymatic cleavage of acetylthiocholine and the resulting thiocholine with Ellman's reagent, DTNB (5,5'-dithiobis-2-nitrobenzoic acid). Results collected in Table 1, revealed following data: almost all tested molecules were able to inhibit reasonably AChE, showing $\mathrm{IC}_{50}$ values ranging from 19.9-34.3 $\mu \mathrm{g} / \mathrm{mL}$ that were compared to those of diazinon, an orgaphosphate AChEl, which has cytotoxic and cytogenetic effects. It is to noted that the most active piperidines 6,7 resulted less cytotoxic in preliminary biotests.

Table 1. AChE inhibitory activity $\left(\mathrm{IC}_{50}\right)$ of the synthesized compounds.

\begin{tabular}{|c|c|c|c|}
\hline \multirow{2}{*}{ Comp. } & \multicolumn{2}{|c|}{$\mathrm{IC}_{50}{ }^{*}$} & \multirow{2}{*}{ CV\% } \\
\cline { 2 - 3 } & $\mathrm{IC}_{50}(\mu \mathrm{g} / \mathrm{mL})$ & $\mathrm{IC}_{50}(\mu \mathrm{M})$ & \\
\hline $\mathbf{5}$ & $34.3 \pm 0.7$ & $1.12 \mathrm{E}-04 \pm 2 \mathrm{E}-06$ & 2.0 \\
$\mathbf{6}$ & $20.1 \pm 0.2$ & $9.31 \mathrm{E}-05 \pm 9 \mathrm{E}-07$ & 1.0 \\
$\mathbf{7}$ & $19.9 \pm 0.8$ & $8.15 \mathrm{E}-05 \pm 3 \mathrm{E}-06$ & 3.9 \\
$\mathbf{8}$ & $41.6 \pm 0.2$ & $1.20 \mathrm{E}-04 \pm 4 \mathrm{E}-07$ & 0.4 \\
& $0.568 \pm 0.008$ & & 1.0 \\
& & $1.87 \mathrm{E}-06 \pm 3 \mathrm{E}-08$ & \\
Diazinon & \multicolumn{3}{|c}{} \\
\multicolumn{3}{|c}{} \\
\end{tabular}

\section{CONCLUSION}

New piperidine-based agents with anti-AChE activities were easy and inexpensive to prepare. These molecules can be useful in further studies on the development of novel insecticidal agents.

\section{ACKNOWLEDGEMENTS}

L.Y.V.M. thanks COLCIENCIAS and USTA by the financial support.

\section{REFERENCES}

${ }^{1}$ Houghton, P. J.; Ren, Y. e Howes, M.-J. Nat. Prod. Rep. 2006, 23,181. 
${ }^{2}$ Kouznetsov, V.V.; Vargas Méndez, L.Y. e Muñoz Acevedo, A. Lett. Drug Des. Disc. 2010, 7, 710

${ }^{3}$ Ellman, G. L.; Courtney, D.; Andres, V. Jr. e Featherstone, R. M.

Biochem. Pharmacol. 1961, 7, 88. 